\title{
La Ciudad y Municipio de Segovia
}

\section{(Conclusión)}

No pretendemos otra cosa en el presente trabajo que recoger y exponer, sucintamente, algunos datos, realidades más destacadas y proyectos que guardan relación con la vida municipal de la ciudad; reunir una pequeña información actual sobre las múltiples facetas de una ciudad como. la nuestra que, a los rancios blasones de su glorioso pasado, une al presente el deseo de vivir a tono con los últimos adelantos de la técnica. Eso es principalmente lo que pretendemos dejar plasmado en estas líneas que siguen, en las que, aunque como antes se dijo, sucintamente, podrá encontrarse noticia sobre el crecimiento de su población, su edificación urbana, su potencial económico, industria y comercio, la acción cultural y benéfica de sus instituciones y sobre todo la acción del Ayuntamiento en orden a todos esos factores, así como otros pormenores que no dejamos de juzgar interesantes.

Para empezar, nada más adecuado que dar una breve noticia sobre el territorio sobre el que se extiende la jurisdicción de la Corporación objeto del estudio.

Geográficamente se halla situado el Municipio a los $40^{\circ} \mathbf{5 7 ^ { \circ }}$ $3^{\prime \prime}$ de latitud Norte y $0^{\circ} 26^{\prime} 24^{\prime \prime}$ de longitud Oeste del meridiano de Madrid, y a poco más de $\mathbf{1 . 0 0 0}$ metros de altitud sobre el nivel del mar.

Su clima es destemplado y frío, como sometido que se encuentra directamente a la influencia de las bruscas alternativas de la vecina Cordillera Central, de là que sólo dista por el Este diez kilómetros escasos. Puede decirse que el verano es corto 
y ardiente, su otoño apacible y bello, el invierno crudo y largo y la primavera destemplada y desigual.

Su temperatura oscila de una máxima de 30 grados a una mínima de 8 bajo cero.

En el término donde se asienta el Municipio forma la población un todo concentrado, sin aldeas, anejos ni poblados desperdigados y ocupa su núcleo urbano aproximadamente la novena parte del término municipal que superficia aproximadamente 19 kilómetros cuadrados.

Población.-Hállase Segovia en la zona de influencia de Madrid, cuyos tentáculos la alcanzan, dando esta circunstancia las consecuencias conocidas en todas las localidades situadas dentro de la esfera de las grandes ciudades tentaculares. Su progreso se halla fuertemente frenado por este hecho y la resistencia ofrecida a su expansión y desarrollo es muy difícil de superar. Ahí está la explicación de la escasa variación que en estas poblaciones limítrofes a Madrid se observa a través de los años, en las que se puede apreciar acaso perfeccionamiento de servicios, mejora de instalaciones, cuidado, arreglo y embellecimiento de su ornato, pero poca, muy poca transformación sustancial y engrandecimiento.

En punto a población, Segovia llegó a albergar en tiempos pretéritos cerca de las $\mathbf{1 0 0 . 0 0 0}$ almas, viviendo una época de gran esplendor cuando sus gremios pregonaban su fama por doquier. Pero la vertiginosa decadencia en la Edad Moderna la redujo de manera brutal. En el siglo actual, su evolución demográfica es así:

Año 1901: 14.658 habitantes; de hecho, 14.547.

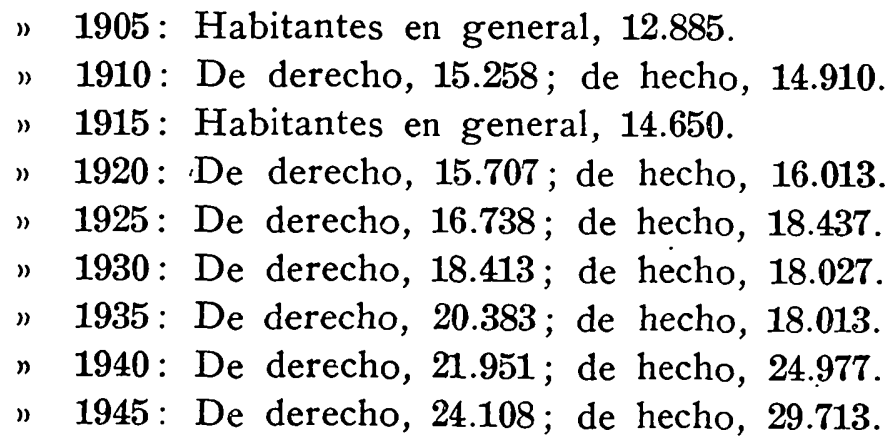


Que para su mayor claridad y comprensión lo expondremos a continuación con más detalles:

\section{Porlación DE DERECHO}

Residentes presentes:

Varones

11.221

Hembras

12.671

Residentes ausentes:

Varones

60

Hembras

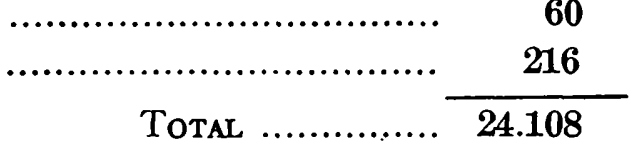

Población de hecho

Residentes presentes:

Varones

11.221

Hembras

12.671

Transeuntes:

Varones

4.680

Hembras

Total

29.713

La clasificación de los habitantes es como sigue:

\begin{tabular}{|c|c|c|}
\hline Vecinos & $\ldots$ & 6.525 \\
\hline Vecinas & & 3.762 \\
\hline Domiciliados & & 4.696 \\
\hline Domiciliadas & $\ldots$ & 8.909 \\
\hline Transeuntes & $\ldots .$. & 4.680 (Var.) \\
\hline Transeuntes & . & 1.141 (Hem.) \\
\hline
\end{tabular}


El número de cabezas de familia, según las cédulas repartidas para la práctica del empadronamiento, es el de 5.727.

Se observa que la variación más sustancial se experimenta desde 1935 a 1945 , en que la población de hecho aumenta un 64 por 100, fenómeno que por manifestarse simultáneamente en todas las ciudades de España en tan corto espacio de tiempo esperamos nos lo expliquen los sociólogos, si bien nosotros opinamos que acaso influya no poco en tales resultados una razón de tipo material: la mayor sinceridad y acusada perfección en la confección de las estadísticas.

\section{VIDA ECONÓMICA}

Es de hacer notar que en el espacio de pocos años nuestra ciudad, caracterizada sobre todo por ser cabeza de una provincia marcadamente agrícola y cerealista, va siendo poco a poco un centro industrial bastante interesante.

Diversos factores que no vamos a analizar en este momento la han lanzado a las empresas industriales, muchas de ellas ya desarrolladas con gran brillantez.

En ella tienen actualmente representación las industrias de la madera, de materiales de construcción en casi toda la gama de sus diversos elementos, como la de la cal, yeso, baldosín, ladrillo, instalaciones higiénicas, materiales refractarios, etc., la del cuero y el calzado, las derivadas del caucho y la protección contra gases tóxidos, la metalúrgica, la de jabones y lejías, la de la cerámica, tanto la artística de gran renombre como la utilitaria, pasando por la de la loza, la de borra y lanas, la de producción de energía eléctrica, la de licores, la de pasta para sopa y galletas, en fin, aparte de las tradicionales de harinas y productos alimenticios.

Floreciente es asimismo su comercio, del que puede decirse existe una casi total representación de las ramas del mismo.

Los ingresos al Tesoro durante el ejercicio de 1946, por el concepto de Industrial, se cifraron en la cantidad de $\mathbf{1 . 6 5 0 . 0 3 8 , 9 4}$ pesetas. 
Por el concepto de Territorial, riqueza rústica y urbana, los ingresos durante el mismo ejercicio fueron de 53.213,91 y 996.920,44 pesetas, respectivamente.

Se produce en el término cereales en su mayor parte, aunque también se recogen patatas, champignon, productos hortícolas, frutas y legumbres.

De las declaraciones presentadas por los agricultores cerealistas del término, se desprende que la superficie dedicada al cultivo de secano en el término municipal es de 547,35 hectáreas, de las que el pasado año fueron sembradas 348,25 .

El resumen de las mismas puede darnos idea clara de los principales cultivos del término, que se descompone de la siguiente forma:

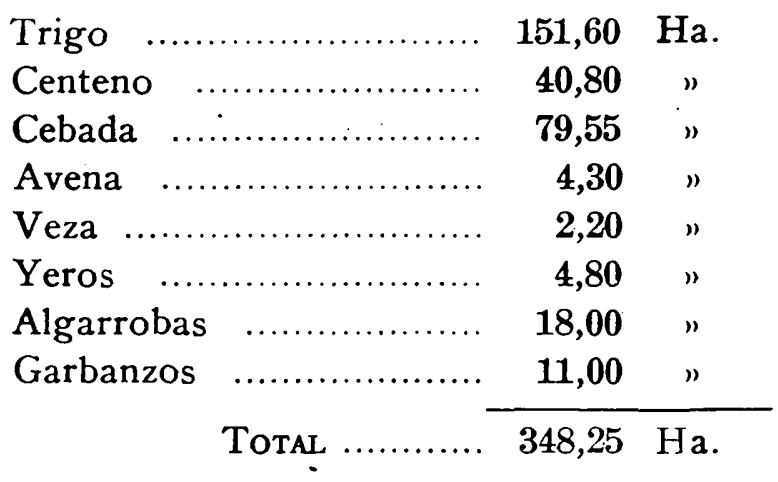

Los productos obtenidos, si nos atenemos a las expresadas declaraciones, han sido los siguientes:

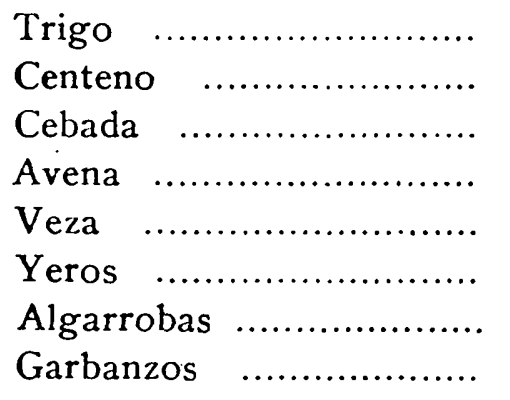

TOTAL
162.318 Kgs.

16.126 "

$145.396 "$

$1.270 "$

$352 "$

$2.082 "$

$6.673 "$

$1.630 "$

335.847 Kgs. 
Las expresadas relaciones comprenden las declaraciones de 46 productores, los que sumados a sus familiares, así como con sus obreros fijos y familiares de éstos, nos da una población agrícola de 295 personas, en las que no van incluídas las productoras de productos hortícolas.

Por regla general, las explotaciones cerealistas son de tipo medio, oscilando las mismas entre una y veinte hectáreas de extensión.

Hace poco tiempo hemos leído que un escritor italiano del siglo xvir se admiraba de que sólo en esta ciudad, en la parrc. quia de San Juan, entre tres ganaderos llegaron a reunir 50.000 ovejas y carneros, pasando de $\mathbf{1 5 0 . 0 0 0}$ cabezas en el resto de la misma, lo que suponía una incomparable riqueza en lana, leche y carne. De esta riqueza de lana nació la industria de fabrica. ción de paños que por aquel entonces hizo famosa a Segovia entre todas las ciudades del mundo.

De ese esplendor nada o casi nada queda en la actualidad.

Una porción de causas reunidas han ido precipitando la decadencia de la riqueza ganadera de la ciudad, dando paso a otras actividades.

La riqueza forestal es casi nula y no da origen a ninguna actividad de orden económico.

Las especies que existen en el término son el pino, que puebla un pequeño monte denominado El Pinarillo; los álamos, acacias, fresnos, sauces y castaños de indias que constituyen el arbolado de la ciudad y que se agrupan principalmente en las márgenes del río Eresma, en las inmediaciones del Monasterio del Parral, en un pintoresco y amenísimo valle que confirma la antigua locución segoviana "De los Huertos al Parral, paraíso terrenal".

No obstante esta carencia de riqueza forestal del término, el Ayuntamiento de la ciudad tiene una buena fuente de sus ingresos en la venta de maderas. Nos referimos a la participación que percibe en las subastas de pinos de los montes pertenecientes a la Comunidad de la Ciudad y Tierra de Segovia, que 
compuesta por cerca de 200 Municipios, el 50 por 100 de los bienes pertenecen al de Segovia, mientras que el otro 50 corresponde a todos los demás.

El estudio de la Comunidad y Tierra de Segovia ofrece, por sí mismo, amplio campo para un libro-alguno existe publicado-por las enseñanzas y curiosidades que encierra. De ahí que lo pasemos por alto en este artículo.

\section{URBANISMO}

Ocupa Segovia, como dijimos al principio, una de las estribaciones de la Cordillera Carpetana, asentándose en la zona o cresta divisoria de los ríos Eresma y Clamores.

Es la ciudad una larga y continua cuesta desde la estación del ferrocarril hasta el barrio de San Marcos y Santuario de Nuestra Señora de la Fuencisla, que constituye a su vez el eje mayor de Segovia.

Ocupa el casco de la ciudad unas $\mathbf{1 3 0}$ hectáreas aproximadamente, y existen en el mismo unos 2.400 edificios, de los cuales son destinados a viviendas 2.100 aproximadamente.

La estructura de los edificios es generalmente a base de casas de tres, dos y planta única. Son contadas las casas de más de tres pisos.

La diferencia de nivel de sus calles es tan grande que la altura máxima de pendiente es de $\mathbf{1 3 8}$ metros del lugar denominado Chamberí a la Alameda del Eresma, y hay dentro de la parte habitada de la ciudad algunos barrios extremos con di. ferencias de 50 a 80 metros.

Es esta, pues, una gran dificultad para la urbanización de la ciudad, por lo que como consecuencia resulta costosísima cualquier reforma y la implantación de cualquier servicio. El alum. brado, pavimentación, alcantarillado, vigilancia nocturna y lis de policía han de resultar en Segovia necesariamente caros.

La causa topográfica es sin duda la que mayores obstáculos pone para lograr la urbanización en la ciudad. La situación en terreno tan accidentado, con tantas pendientes y desniveles que 
ha obligado a la construcción de zanjas, escalinatas, pretiles, muros de contención, influye de manera notable con relación a lo que dejamos dicho.

Hasta mediados del siglo pasado en que comenzó realmente la reforma urbana de Segovia, las edificaciones se hacían guardando la forma de calles y plazuelas, pero sin sujeción a ningún plan ni ordenamiento municipal, y así se construía alto y bajo, con salientes, con aleros, con rinconadas; y aun en las mismas casas se ven pisos a distinto nivel, y como resultante de todo lo dicho un abigarramiento y un completo desorden en los edificios.

Consciente el Ayuntamiento de que las calles de la ciudad son algo así como el sistema nervioso de la urbe y que por las calles de un pueblo juzgamos en seguida su cultura, de su adelanto moral y material, de su higiene y de su administración, ha emprendido no hace mucho y a fondo lo que pudiéramos llamar la verdadera reforma urbanística de la ciudad, consistente, en trazos generales, al adecentamiento de la parte antigua, evitando los atentados contra la estética de la misma, muy notable, y procurando reformarla con arreglo a la técnica moderna en lo que no se oponga al verdadero carácter de ella; y, por otra parte, en la creación que pudiéramos decir de la parte nueva de la ciudad o Zona de ensanche de la misma. A este fin se estimó como más conveniente la construcción de una pista en la Zona de ensanche, la que actua'mente se ha convertido ya en magnifica realidad.

Esta pista representará en lo futuro el eje urbano de aquella nueva Zona y se extiende desde el cuartel de Artillería hasta el polígono de las Baterías, y se ha llevado a efecto con fondos del Estado en terreno de propiedad municipal y otros adquiridos previamente por el Ayuntamiento.

El ensanche en la Zona de referencia está llamado a adquirir gran relieve, ya que la disposición natural de la ciudad impone su extensión por la misma predisposición que ädemás sera ayudada por la acción urbanizadora del Ayuntamiento.

Esta pista o especie de Gran Vía será, como dejamos dicho, un eje al lado del cual tomarán carácter urbano las zonas limí. 
trofes que hoy le tienen esencialmente rural y así se convertirá en solares debidamente alineados donde se levantarán las futuras edificaciones que con el centro municipal darán vida a la nueva ciudad, de la que serán iniciación el grupo de 174 viviendas que actualmente y por cuenta del Ayuntamiento se encuentran en construcción y cuya situación es en una de las márgenes de la vía en cuestión.

Como quiera que todos los terrenos limítrofes de ésta son propiedad municipal, queda asegurada en debida forma su urbanización, plenamente garantizada, y se evitará el agio y especulación de terrenos evitando que la actividad y el esfuerzo económico que aportó el Ayuntamiento para la construcción de la misma sean aprovechados con fines lucrativos por los particulares.

No puede olvidarse al hablar de la urbanización de Segovia que toda la ciudad, situada dentro del recinto amurallado, está declarada oficialmente "Monumento Nacional" por Decreto de 12-7-1941, lo cual establece férreas restricciones a la actividad de este orden y frena muy poderosamente las iniçiativas en punto a transformaciones de su ornato o de su aspecto. Es menester por ello hacer compatibles los avances urbanísticos con un absoluto respeto al carácter y fisonomía de la ciudad, lo cual en realidad no tiene nada de fácil.

\section{Servicios municipales}

Tiene el Excmo. Ayuntamiento establecidos en la actualidad los siguientes servicios:

Servicio de agua potable.

Tuvo ya Segovia agua abundante desde la época romana merced a la construcción del maravilloso Acueducto, emblema de la ciudad; pero la conducción actual de aguas data de muy antiguo, si bien fué sensiblemente modificada y acondicionada en el año 1928. 
Proceden las aguas de Segovia del arroyo Aceveda, que nace en la vertiente septentrional de la Cordillera Central. Son aguas claras, puras, sin la menor traza de olor ni sabor, no conteniendo materia orgánica apreciable ni más sustancias disueltas que el aire, lo que se explica porque generalmente la superficie de la cuenca presenta al descubierto rocas primitivas de granito y. gneis. La longitud de la conducción de aguas es, hasta los depósitos, de 13 kilómetros, de los que dos y medio corresponden dentro del término y los diez y medio restantes fuera del mismo.

La conducción es abierta en los primeros 300 metros y cubierta en los restantes a base de tubo de cemento de 0,50 y 0,40 de sección.

Aunque la distancia desde el origen a los depósitos y las buenas condiciones que para la bebida reune el agua son la garantía más eficaz para destruir los gérmenes peligrosos, existe instalada una estación depuradora por el sistema de cloración con la suficiente capacidad de tratamiento.

Los depósitos son dos, con una capacidad global de $\mathbf{4 0 . 0 0 0}$ metros cúbicos, y se hallan perfectamente acondicionados.

Exisen 1.618 abonados a este servicio y los contadores instalados son 4.361 .

Consume diariamente la población unos 1.081 metros cúbicos. Las tarifas del servicio son como siguen: para usos domésticos, un mínimo de ocho metros cúbicos en verano y doce en invierno, que se cobra proporcionalmente al alquiler de viviendas, añadiendo dos metros cúbicos más a las familias que tengan ocho o más miembros.

El exceso de consumo sobre los metros indicados se cobra a razón de 0,40 pesetas en verano y 0,25 en invierno. Para usos industriales, en verano a $\mathbf{0 , 5 0}$ pesetas el metro hasta 500 y a 0,25 los restantes.

La casi totalidad de los edificios de la población se encuentran abastecidos de agua, pudiendo asegurarse que no llegan a 500 personas las comprendidas en el núcleo de las que carecen de abastecimiento domiciliario. 
La red de distribución alcanza aproximadamente una longitud de 20 kilómetros.

El servicio que se encuentra municipalizado y monopolizado, y abocado a una transformación total, en virtud de las obras que en la actualidad se están llevando a cabo para dotar a la capital de un nuevo abastecimiento que alcanzará a suministrar agua para una población doble de la actual, o sea, para unos 60.000 habitantes aproximadamente, a razón de 230 litros por habitante y día, lo que supone una previsión para cincuenta años.

Consisten las obras de que queda hecha mención, ya que las mismas se encuentran en la actualidad en plena ejecución, en la construcción de una presa de 33 metros de altura para constituir un embalse capaz para 2.500.000 metros cúbicos, y una conducción con una longitud de 11 kilómetros hasta los depósitos, situados en las inmediaciones de la capital. Como obras complementarias de las reseñadas, figuran también las de cubrir los depósitos, actualmente descubiertos, y la de ampiiación de la estación depuradora.

El presupuesto total de estas obras rebasa la cifra de 12 millones de pesetas. Con la ejecución de estas obras el abastecimiento de agua de la ciudad dejará de constituir un problema para la misma y se evitará la escasez y la restricción que en los meses de estiaje se deja sentir.

El servicio de agua de la ciudad queda completamente asegurado con las 25 fuentes públicas existentes, dos abrevaderos, tres evacuatorios, dos lavaderos y las $\mathbf{1 7 7}$ bocas de riego situadas convenientemente dentro de la ciudad.

Otro de los servicios establecidos es el de

\section{Cementerio}

Que por el esmero y cuidado de que el mismo es objeto puede asegurarse que constituye un modelo en su género. Es acaso el más brillante de los que este Ayuntamiento tiene establecidos. 
Consciente el Ayuntamiento de la atención que debe prestarse a este servicio a fin de que no pueda presentarse conflicto o apuro en materia de enterramiento, ha sido, no hace mucho tiempo, ampliado a más del doble, y se han mejorado notablemente sus instalaciones, construyéndose nuevo pabellón de autopsias, depósito de cadáveres, etc., todo ello con arreglo a la técnica moderna.

Consta en la actualídad de tres patios que ofrecen un magnífico aspecto que es objeto de constante y continua superación.

En el patio últimamente construído se están verificando obras consistentes en la construcción de galerías de laudes y existe ya el proyecto de construir otras de nichos, que pronto se hará realidad.

A su servicio se hallan un capellán, cuatro sepultureros, un sacristán y un jardinero, si bien es de tener en cuenta que el magnífico aspecto que presenta es debido en gran parte al personal temporero que constantemente absorbe este scrvicio.

El servicio de vigilancia y seguridad corre a cargo de la Guardia municipal, diurna y nocturna.

Consta la primera de un Jefe y treinta números y su cometido es, como se sabe, la vigilancia pública, a fin de prevenir las faltas e infracciones de las Ordenanzas y bandos municipales, corregirlas en su caso y formular las denuncias oportunas a la autoridad. Representa también un elemento de colaboración de las fuerzas de orden público con las que coopera al fin de su mantenimiento.

La ampliación que recientemente se ha hecho de la plantilla del personal adscrito a este servicio y el sometimiento del mismo a una rígida disciplina militar, ha empezado pronto a dar sus frutos, por lo que confiadamente se espera en que el servicio quede montado con toda la eficiencia y decoro que el rango de la ciudad exige y sea modelo en su género. Todo este personal se encuentra perfectamente uniformado.

La Guardia municipal nocturna o Cuerpo de Serenos tiene idéntica misión que la diurna, más el tradicional y conocido cometido de poseer las llaves de los edificios.

También recientemente se ha aumentado su plantilla, si bien 
no en el número de da diurna. Su número actual es de veinticuatro, más cuatro serenos llamados de comercio.

No tiene municipalizado el Ayuntamiento el servicio de transportes de la ciudad, existiendo solamente una empresa particular que regularmente efectúa el transporte de viajeros de la estación de ferrocarril a la plaza de Franco. Queda completado este servicio con los 33 automóviles taxímetros autorizados por el Ayuntamiento para prestar servicio en la capital.

Los parques y jardines existen en gran profusión en la ciudad, y aunque ofrecen los más de ellos un agradable aspecto no pueden estar los mismos atendidos debidamente por la desproporción entre su número y el del personal encargado de su custodia y conservación, que naturalmente tiene que ser limitado y con arreglo a las posibilidades del erario municipal.

La mayor eficacia que se espera obtener del Cuerpo de la Guardia municipal, recientemente organizado como antes queda dicho, repercutirá indudablemente en beneficio de la conservación de los jardines que embellecen nuestra ciudad.

El servicio de alcantarillado, estrictamente municipal, extiende sus ramificaciones por todas las calles de la ciudad y está perfectamente atendido.

Alcanza la longitud de su red unos veinte kilómetros aproximadamente, igual que la de aguas potables, de la que unos dos kilómetros son visitables.

El. número de edificios servidos viene a ser sensiblemente el mismo de los que tieren establecido el agua.

Otro de los servicios que tiene establecido el. Ayuntamiento es el de matadero. Se halla éste instalado en el edificio conocido antiguamente con el nombre de "Casa del Sol", en la misma muralla que circunda la ciudad, edificio que entre otros usos ha tenido el de convento; de ahí que no reuna las condiciones precisas para el fin que han de cumplir esta clase de establecimientos.

Consta el matadero municipal de dos naves, una para el ganado vacuno y lla otra para el lanar, cabrío y de cerda.

Las deficiencias que en el edificio se observan hace que se imponga la construcción de uno nuevo o bien modificar y me- 
jorar en gran escala el actual, ya que ni la capacidad, instalaciones ni procedimientos de sacrificios corresponden a las exigencias de la vida presente. A este respecto el Ayuntamiento se encuentra decidido a dar rápida solución al problema, a cuyo fin se han dado ya los primeros pasos con la adopción de pertinentes acuerdos.

Constituye el matadero una buena fuente de ingresos para el Municipio. El número de reses sacrificadas en el mismo ha sido durante el pasado año el siguiente:

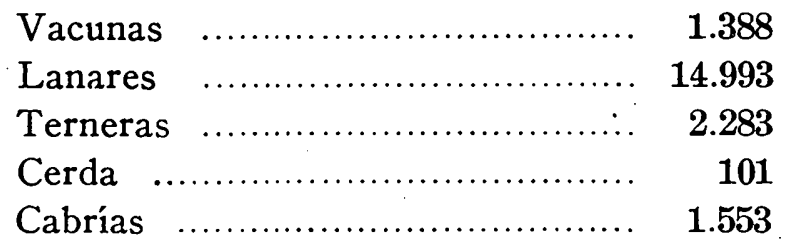

Los ingresos que produjo al Ayuntamiento durante el mismo período de tiempo se cifran en $\mathbf{1 9 7 . 1 1 4 , 6 6}$ pesetas.

Al frente del establecimiento figura un Administrador y en el aspecto técnico un Inspector Veterinario.

El servicio de acarreo de carnes desde el matadero hasta los distintos establecimientos expendelores se hace por medio de camionetas "ad-hoc), de propiedad municipal.

El servicio de incendios es objeto de continua perfección, tenido en clienta la importancia del mismo. La adquisición de material moderno que recientemente se ha hecho le han colocado en forma que puede cumplir con toda eficiencia su cometido.

Depende este servicio del Arquitecto municipal y lo componen además un mecánico conductor, dos capataces, veintitrés bomberos de primera y diez de segunda.

El servicio de limpieza de la vía pública corre a cargo de barrenderos municipales en número de treinta y dos, insuficiente a todas luces si se tiene en cuenta la superficie que va teniendo la ciudad, por lo que, y para mantener ésta en las condi. ciones debidas de higiene y pulcritud, es preciso tomar personal temporero en determinadas épocas y principalmente en la de nevadas. 
El servicio de limpieza de la ciudad queda completado con el de retirada de basuras, tanto domiciliarias como las procedentes de las vías públicas. Este último servicio de retirada y alejamiento de basuras le tiene arrendado el Ayuntamiento a una Sociedad por el precio de $\mathbf{5 . 0 0 0}$ pesetas anuales y cuyo contrato vence en el año 1949.

La desaparición de las camionetas de este Ayuntamiento que venían prestando este último servicio, la restricción de gasolina y otros factores obligaron a aceptar la solución de arrendamiento del servicio, que se viene efectuando definitivamente como mal menor.

Problema es este que viene preocupando a este Excelentísimo Ayuntamiento, si bien confiadamente se espera que dé resultado en forma satisfactoria en breve plazo. La adquisición que recientemente se ha hecho de dos magníficos camiones y una coordinación entre estos dos servicios será sin duda alguna su solución, con lo que evitará el aspecto antiestético que ofrecen los carros descubiertos y mal acondicionados al circular cargados de basuras por las calles de la capital.

El servicio de alumbrado de la ciudad, todo por electricidad, deja en algunos sitios bastante que desear, pero en general puede calificársele de bueno.

Corre a cargo el servicio de una empresa particular en virtud de contrato que tiene celebrado con el Excmo. Ayuntamiento, al que supone un gasto anual por este concepto de $\mathbf{8 0 . 0 0 0}$ pesetas.

Pronto pasará a ser realidad el proyecto existente de nuevo alumbrado de la plaza de Franco, de las calles de Isabel la Católica y Cervantes, que hoy se encuentra pendiente de la realización de pequeños trámites administrativos, con lo que las expresadas vías, las de mayor importancia y céntricas de la ciudad, quedarán iluminadas con arreglo a la técnica moderna seguida en las más importantes capitales españolas.

El servicio de mercados se encuentra suficientemente abastecido.

La construcción de dos modernísimos mercados de zona en lugares estratégicos de la población ha venido a sustituir a los 
que al descubierto se venían celebrando en plazas y lugares públicos.

Se han situado los mismos en la Zona norte y sur de la ciudad y han sido construídos directamente por el Ayuntamiento. Con ellos se ha conseguido eliminar los malos olores, evitar la suciedad que antes se producía y centralizar los diversos puestos que existían diseminados por las calles de la ciudad.

Uno de los mercados tiene treinta y un puestos y nueve mesas y el otro veintidós puestos, expendiéndose en los mismos todos los géneros propios del mantenimiento público.

No existen mercados particulares.

No tiene establecido el Ayuntamiento servicios de laboratorio, pero los de esta naturaleza son prestados por el Instituto Provincial de Sanidad.

El servicio de Beneficencia municipal alcanza a 225 familias pobres, las que disfrutan de los beneficios de asistencia médicofarmacéutica gratuita.

Existen adscritos a este servicio cinco médicos de asistencia pública domiciliaria y otras tantas farmacias para la expendición de medicamentos.

La Casa de Socorro recientemente trasladada a un moderno y céntrico edificio de la capital, se encuentra perfectamente dotada y atendida. La plantilla de la misma está compuesta por tres médicos y tres practicantes.

No existe Hospital municipal, pero el Ayuntamiento contribuye voluntariamente con 20.000 pesetas al sostenimiento del provinciai.

Subvenciona también el Ayuntamiento a diversas instituciones benéficas, entre las que se cuentan el Asilo de Ancianos, Refugio de Pobres, Asilo de las Hermanitas de los Pobres, Siervas de María, Cruz Roja Española, Religiosas Oblatas y Atxilio Social, disponiendo asimismo de un fondo especial para el socorro y conducción de pobres transeuntes.

En lo que se refiere a la Instrucción Pública, viene el Ayuntamiento prestando al Estado su colaboración mediante el' cumplimiento de las obligaciones que en este orden impone la ley. Viene satisfaciendo el Ayuntamiento el alquiler por casa habi- 
tación que ocupan los maestros nacionales de la ciudad, el que recientemente y en atención a las dificultades y carestía de las viviendas ha sido aumentado; subvenciona también la calefacción de las referidas escuelas y el pago del alquiler de los locales ocupados por varias de éstas. Las restantes están alojadas en grupos escolares propiedad de este Ayuntamiento.

Sostiene también el Ayuntamiento el funcionamiento de un Gimnasio municipal, Escuela de Artes y Oficios y consigna en . su presupuesto ordinario de gastos las correspondientes partidas para subvencionar a diversas Sociedades de Amigos de la Escuela, Universidad Popular, C. N. S., Frente de Juventudes, Seminario Conciliar, Centro Segoviano de Madrid, para becas a estudiantes universitarios, Escuela del Hogar de Falange Española Tradicionalista y de las J. O. N. S., Academia Católica de Obreras y otras más.

En ejecución se encuentra ya un nuevo y grande grupo escolar, en las inmediaciones de la Pista Militar, junto a las viviendas protegidas que este Ayuntamiento está construyendo, que acoja a la población infantil! que por insuficiencia de los existentes no puede recibir instrucción.

Sólo existe una escuela de carácter municipal.

Los centros docentes que existen en esta capital son:

\section{A) Enseñanza Primaria:}

\begin{tabular}{|c|c|c|}
\hline Graduadas & & 5 \\
\hline Unitarias & $\cdots$ & 3 \\
\hline Mixtas & & 2 \\
\hline Párvulos & $\ldots \ldots$ & 4 \\
\hline $\begin{array}{r}\text { Colegios } \\
\text { ñanza }\end{array}$ & $\begin{array}{l}\text { articulares de Ense- } \\
\text { rimaria } \ldots \ldots \ldots \ldots \ldots \ldots . . . \ldots\end{array}$ & 9 \\
\hline
\end{tabular}

B) Enseñanza Media:

Instituto de Enseñanza Media.

Cuatro Colegios.

Cuatro Colegios de Enseñanza Media. 
C) Magisterio:

Escuelta Normal.

D) Enseñanza Militar:

Academia de Artillería.

E) Enseñanzas Religiosas:

Seminario Conciliar.

F) Enseñanzas especiales:

Escuela Elemental del Trabajo.

Escuela de Artes y Oficios.

G) Bibliotecas :

Universidad Popular.

Academia de Artillería.

Diputación Provincial.

Educación y Descánso.

H) Museos y Archivos:

Museo Provincial.

Museo Diocesano.

Archivo General Militar.

Archivo Provincial.

Archivo Municipal.

SOCIEDAD FILARMÓNICA

Existe también consignada en presupuesto una cantidad para pago a la Banda de Música de la Academia de Artillería por los conciertos contratados que celebra en los paseos de la ciudad durante el año. 


\section{HACIENDA MUNICIPAL}

La evolución de los presupuestos ordinarios del Ayuntamiento dentro del siglo presente, es como sigue:

\section{Presupuestos}

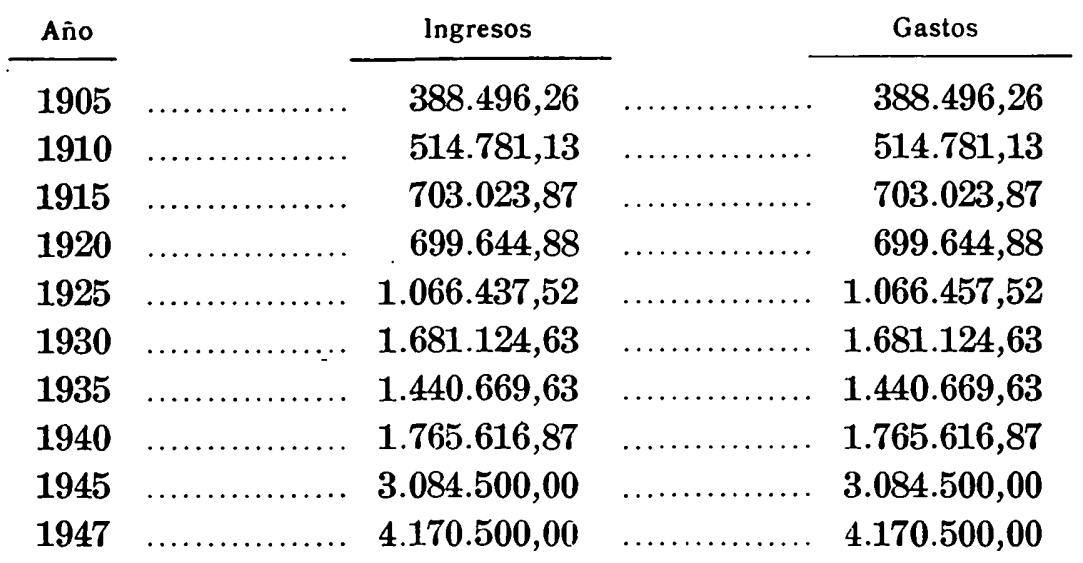

Se puede apreciar que la publicación de la nueva Ley de Bases de Régimen Local con su complemento del Decreto de Ordenación Provisional de las Haciendas Locales de 25. de enero de 1946, ha repercutido en la de este Municipio con un aumento de presupuesto de un millón de pesetas.

Los presupuestos extraordinarios se suceden los unos a los otros sin interrupción, ya que apenas liquidado uno ya está otro en vigor cuando no coexiste un par de ellos. Al presente sólo hay uno en vigor por un importe de $\mathbf{1 3 . 5 0 0 . 0 0 0}$ pesetas, destinado a las obras de abastecimiento de agua y a unificación de deuda. La deuda municipal se reduce a la suma de 13.500.000 pesetas, igual al presupuesto extraordinario; consistente en un préstamo concedido por el Banco de Crédito Local, pero del que sólo se ha dispuesto hasta el momento de 5.557.835,60 pesetas.

Puede observarse que la fortaleza de la hacienda de este 
Municipio es sólida y ya que la ciudad sea modesta y no pueda deslumbrar con fulgores de tipo suntuario, al menos tiene potencia y vitalidad singulares en su categoría.

El patrimonio comunal se halla cifrado en inventario de la cantidad de 461.283 pesetas, cifra muy baja en relación con su valor real si tenemos en cuenta que las propiedades en montes de aprovechamiento forestal valen hoy sumas difícilmente calculables dado el precio que adquieren las maderas en las subastas que se celebran.

Los recursos ordinarios para nutrir el presupuesto son los conocidos de todos, que la ley autoriza, pudiendo señalarse como principales fuentes de ingresos el aprovechamiento de montes, servicio de agua potable, impuestos cedidos por el Estado (Usos y Consumos, tarifa 5. ${ }^{\mathrm{a}}$ ); derechos y tasas por prestación de servicios y aprovechamientos especiales; vinos y alcoholes; carnes; plus valia, etc., etc.

\section{Personal}

El personal dependiente del Ayuntamiento se halla encuadrado en la plantilla siguiente:

Un Secretario General.

Un Interventor de Fondos.

Un Depasitario de Fondos.

Un Arquitecto.

Un Ingeniero.

Un Aparejador.

Un Jefe de Negociado de 1.:

Dos Jefes de Negociado de 2:.

Cutro Oficiales de Negociado de 1.*.

Cuatro Oficiales de Negociado de 2.:

Tres Auxiliares de Negociado de 1.

Cuatro Auxiliares de Negociado de 2.:

Un Conserje.

Tres Alguaciles.

Un Portero. 
Un Botones.

Un Inspector.

Un Jefe de la Guardia Municipal.

Treinta Guardias Municipales.

Un Jefe de Serenos.

Veinticuatro Serenos.

Un Chófer.

Cuatro Bomberos.

Un Administrador del Matadero.

Dos Administradores de Mercados.

Un Matarife de 1..

Cinco Matarifes de $2 .^{2}$.

Un Aprendiz de 1. ${ }^{\mathrm{a}}$.

Un Aprendiz de 2. .

Un Portero del Matadero.

Dos Cargadores del Matadero.

Un Inspector de Arbitrios.

Un Subinspector de Arbitrios.

Un Recaudador General de Arbitrios.

Un Auxiliar General de Arbitrios.

Cuatro Recaudadores Interventores de Arbitirios de 1.:

Dos Recaudadores Interventores de Arbitrios de 2.*.

Ocho Auxiliares de Recaudador.

Un Maestro fontanero.

Un Oficial de fontanería.

Un Auxiliar de fontanería.

Dos Lectores de Contadores.

Cuatro Guardas de Cacera.

Un Guarda de los depósitos.

Un Capellán del Cementerio.

Un Sacristán del Cementerio.

Dós Sepultureros.

Dos Vigilantes nocturnos.

Un Cabo de Arbitrios.

Treinta y nueve Vigilantes de Arbitrios.

Un Maestro carpintero.

Un Maestro de obras. 
Cuatro Oficiales de albañilería.

Un Mecánico conductor.

Cuatro Peones Camineros.

Un Director de arbolado.

Un Capataz de arbolado.

Un Cabo de arbolado.

Once Guardas de arbolado.

Dos Aprendices de arbolado.

Un Carretero de arbolado. .

Un Cabo de Montes.

Tres Guardas de Montes.

Un Chófer de limpieza.

Treinta y dos Barrenderos.

Dos Encargados de lavaderos.

Dos Encargados de evacuatorios.

Un Director del Gimnasio Municipal.

Cinco médicos de Asistencia Pública Domiciliaria.

Tres Médicos de la Casa de Socorro.

Cuatro Practicantes de la Casa de Socorro.

Una Matrona de la Casa de Socorro.

Un Portero de la Casa de Socorro.

Cinco Farmacéuticos.

Un Odontólogo.

Tres Veterinarios.

Dos Usos y Consumos.

Dos mujeres encargadas de la limpieza de Oficinas.

Independientemente de sus haberes todo el personal goza de diversos beneficios, como son dos gratificaciones anuales, importe cada una de una mensualidad; subsidio familiar; plus por cargas familiares con arreglo al juego de los puntos; un seguro de vida igual al importe de sus haberes anuales, cuyas primas satisface integramente el Ayuntamiento; abono del impuesto de utilidades por ell Ayuntamiento, más los quinquenios, licencias, jubilaciones y demás ventajas reglamentarias. 


\section{Proyectos más importantes}

Entre los proyectos más importantes, todos en vías de realización, que dotarán a Segovia de servicios interesantes y contribuirán en medida muy apreciable a su mejora general, figuran la fábrica de carros de combate y tractores, cuya construcción ocupará un solar de 40.000 metros cuadrados y está adjudicada su construcción à la Sociedad "Cimientos y estructuras"; la Estación central de autos de línea patrocinada por el Ministerio de Obras Públicas; la gran vía de enlace a través del Azoguejo, obra delicada por las expropiaciones urbanas que es menester acometer con su secuela de desalojamiento de industrias y viviendas, también con cargo al Ministerio de Obras Públicas; el gran edificio que construye la S. A. Inmobiliaria Segoviana en plena calle de Juan Bravo para ser destinado a hotel, cinematógrafo, bar, etc.,.y en el que se recogen los modernos avances en materia de confort; línea de trolebuses que emlace y comunique la ciudad en sentido longitudinal; continuación del plan de viviendas hasta la cifra de 500 que abarca el primitivo; el gran bloque de casas que en la calle de José Zorrilla se construya con carácter particular, y otros de menor cuantía que, junto con la resolución definitiva, amplia y completa del problema de abastecimiento de agua, representarán para Segovia un fuerte impulso en su camino de transformación y modernización a la que la iniciativa privada colaborará en gran medida una vez abiertos por el poder público los caminos que la favorecen, entre los que representa un papel inapreciable la electrificación del ferrocarril, 'que permite el establecimiento de numerosos trenes que con rapidez y comodidad enlazan con la capital de España.

José María Peláez Suárez

Secretario del Ayuntamiento de Segovia. 